\title{
Publisher Correction: Genomic instability in mutant p53 cancer cells upon entotic engulfment
}

\author{
Hannah L. Mackay ${ }^{1,10}$, David Moore ${ }^{1,2}$, Callum Hall ${ }^{3}$, Nicolai J. Birkbak ${ }^{4,5}$, Mariam Jamal-Hanjani ${ }^{6,7}$, \\ Saadia A. Karim ${ }^{8}$, Vinaya M. Phatak ${ }^{1}$, Lucia Piñon', Jennifer P. Morton ${ }^{8,9}$, Charles Swanton ${ }^{4,5,6}$, \\ John Le Quesne ${ }^{1,2,9}$ \& Patricia A.J. Muller ${ }^{1,3}$
}

Correction to: Nature Communications https://doi.org/10.1038/s41467-018-05368-1; published online 03 August 2018

The original version of this article incorrectly omitted an affiliation of Patricia A. J. Muller: 'Cancer Research UK Manchester Institute, The University of Manchester | Alderley Park, Manchester, SK10 4TG, UK'. This has been corrected in both the PDF and HTML versions of the article.

Published online: 28 August 2018

Open Access This article is licensed under a Creative Commons Attribution 4.0 International License, which permits use, sharing, adaptation, distribution and reproduction in any medium or format, as long as you give appropriate credit to the original author(s) and the source, provide a link to the Creative Commons license, and indicate if changes were made. The images or other third party material in this article are included in the article's Creative Commons license, unless indicated otherwise in a credit line to the material. If material is not included in the article's Creative Commons license and your intended use is not permitted by statutory regulation or exceeds the permitted use, you will need to obtain permission directly from the copyright holder. To view a copy of this license, visit http://creativecommons.org/licenses/by/4.0/.
\end{abstract}

(C) The Author(s) 2018

\footnotetext{
${ }^{1}$ MRC Toxicology Unit, Lancaster Road, LE1 9HN Leicester, UK. ${ }^{2}$ Cancer Studies, University of Leicester, Leicester LE1 7RH, UK. ${ }^{3}$ Cancer Research UK Manchester Institute, The University of Manchester | Alderley Park, SK10 4TG Manchester, UK. ${ }^{4}$ Translational Cancer Therapeutics Laboratory, The Francis Crick Institute, 1 Midland Rd, London NW1 1AT, UK. ${ }^{5}$ Cancer Research UK Lung Cancer Centre of Excellence, University College London Cancer Institute, Paul O'Gorman Building 72 Huntley Street, London WC1E 6BT, UK. ${ }^{6}$ Department of Medical Oncology, University College London Hospitals, 235 Euston Rd, Fitzrovia, London NW1 2BU, UK. ${ }^{7}$ CRUK The Beatson Institute, Garscube Estate, Switchback Road, Glasgow G61 1BD, UK. ${ }^{8}$ Institute of Cancer Sciences, University of Glasgow, Switchback Road, Glasgow G61 1BD, UK. ${ }^{9}$ Department of Histopathology, Glenfield Hospital, University Hospitals Leicester NHS Trust, Groby Road, Leicester LE3 9QP, UK. ${ }^{10}$ Present address: Institute of Cancer and Genomic Sciences, University of Birmingham, Birmingham B15 2TT, UK Correspondence and requests for materials should be addressed to J.Q.L. (email: jlq2@le.ac.uk) or to P.A.J.M. (email: patricia.muller@manchester.ac.uk)
} 